\title{
The walking interview: Methodology, mobility and place
}

\author{
James Evans ${ }^{\mathrm{a}, *}$, Phil Jones ${ }^{\mathrm{b}}$

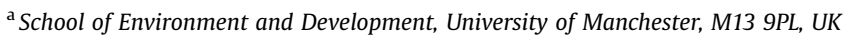 \\ ${ }^{\mathrm{b}}$ School of Geography, Earth E Environmental Sciences, University of Birmingham, B15 2TT, UK
}

Keywords:

Walking interviews

Place

Qualitative GIS

Place discourse

Mobile methodologies

\begin{abstract}
A B S T R A C T
Social scientists have begun engaging with participants 'on the move' in a variety of ways. This paper presents the results of a pilot study, which deployed a qualitative GIS technique to analyse the effectiveness of walked interviews in capturing data relating to people's understanding of place. We give an account of the walking interview exploring two issues: the relationship between what people say and where they say it; and qualitative and quantitative differences between data generated by walking and sedentary interviews. Our results indicate that the data generated through walking interviews are profoundly informed by the landscapes in which they take place, emphasising the importance of environmental features in shaping discussions. We also demonstrate a measureable difference between walking and sedentary techniques in the production of rich place narratives both in terms of their quantity and spatial specificity to the study area. The paper concludes by acknowledging that a technocentric analysis of place runs the risk of emphasising locational above humanistic elements, but argues that, done sensitively, a qualitative GIS approach offers great potential for engaging planners and policy makers with the importance of local connections to place.
\end{abstract}

(c) 2010 Elsevier Ltd. All rights reserved.

\section{Introduction}

Over the last few years a small but growing number of social scientists and geographers have been using techniques where researchers walk with participants (for example, Anderson, 2004; Carpiano, 2009; Kusenbach, 2003; Reed, 2002). Studies vary from those where researchers simply wander through landscapes chatting with participants, to highly structured tours that are designed to elicit responses to specific, predetermined places. It is argued that walking interviews generate richer data, because interviewees are prompted by meanings and connections to the surrounding environment and are less likely to try and give the 'right' answer. Indeed, it seems intuitively sensible for researchers to ask interviewees to talk about the places that they are interested in while they are in that place. There are, of course, limitations: to be relevant, research questions need to be framed by a 'place' that can be walked, and the act of walking will exclude certain types of participants and interviewing techniques.

In this paper we seek to examine some of the intuitive assumptions about the usefulness of walking with participants. As part of a pilot project, we have chosen to examine notions of place,

\footnotetext{
* Corresponding author. Tel.: +44 121414 5546; fax: +44 1214145528.

E-mail addresses: jp.evans@manchester.ac.uk (J. Evans), p.i.jones@bham.ac.uk (P. Jones).
}

to test the hypothesis that walked interviews give access to richer understandings of place than can be generated by more conventional interviewing techniques. This is a deliberately limited and exploratory assessment of this method, which opens the door to further research looking at other aspects of the walked interview process. The paper presents results from the Rescue Geography project, which developed a technique using a form of qualitative GIS to examine the walk and talk method and its effectiveness in recovering community attachment to place. First, we examine some of the effects that location has on how the walking interviews unfold. Second, we compare data gathered on the same project from both sedentary and walking interviews. We conclude by examining the usefulness of walking interviews in general - and the qualitative GIS technique we have developed in particular - to bring more nuanced understandings of place into planning policy. This is of particular importance given the current emphasis on sustainable and inclusive planning where practitioners are having to pay increasing attention to how individuals and communities value the spaces in which they live.

\section{The walking interview: methodological issues}

Mobility and mobile methods have attracted significant academic attention across the social sciences in recent years. Sheller and Urry (2006) have identified the formation of a new 'mobilities paradigm', as geographers have become increasingly 
interested in new technologies that have both made aspects of modern life more mobile, and facilitated new ways of studying these phenomena (for a review of the theory, technologies and practice of mobile methods see Fincham, McGuinness, \& Murray, 2010; Ricketts Hein, Evans, \& Jones, 2008). Our work on walking fits within this broad context, both in terms of how mobility offers a valuable perspective on the world, and how technologies such as GIS and GPS can help capture and represent those perspectives.

A distinction should be made here between the broad category of mobile methods and what might be described as sedentary methods in motion. The mobilities debate has highlighted different scales of movement, from the flickering of eyelids to the transnational movement of migrant bodies (Merriman et al., 2008). We would argue that there is a distinct difference between the experience of interviewing participants, say, on a train where movement is experienced as a visual flow through windows and the primary haptic sensation is merely that of background vibration (Bissell, 2010) compared to doing so whilst cycling up a French alp (Spinney, 2006). Walking in the street (as against, say, being driven around in a car e.g. Laurier \& Philo, 2003) means that both researcher and participant are more exposed to the multi-sensory stimulation of the surrounding environment (Adams \& Guy, 2007), rather than cocooned in a filtered 'blandscape' (Bijsterveld, 2010; Edensor, 2007). This gives an immediacy as well as a kinaesthetic rhythm (Middleton, 2009) that makes for a different experience to those methods which, though undertaken while in motion, are essentially sedentary from the bodily perspective of the participant/researcher.

The literature suggests that a major advantage of walking interviews is their capacity to access people's attitudes and knowledge about the surrounding environment. Walking has long been considered a more intimate way to engage with landscape that can offer privileged insights into both place and self (Solnit, 2001). Ingold and Lee (2008) suggest that walking with interviewees encourages a sense of connection with the environment, which allows researchers to understand how, for example, places are created by the routes people take. Wylie (2005) offered a specifically biographical take on this approach, using a walking holiday along part of England's South West Coast Path as a prompt for his own personal reflections on embodiment, affect and engagement with landscape. A more commonly used approach is the hybrid of interviewing and participant observation known as a 'go-along'; the researcher walks with interviewees as they go about their daily routines, asking them questions along the way (Carpiano, 2009; Kusenbach, 2003). As such, the go-along is similar to the 'shadowing' technique familiar to organisational researchers (McDonald, 2005), although with perhaps a greater emphasis on the movements between different locations. Kusenbach (2003) argues that go-alongs can capture the sometimes hidden or unnoticed habitual relations with place and the environment because it has a tendency to highlight environmental perception, spatial practices, biographies, social architecture and social realms in the data gathered. Hitchins and Jones (2004) used a similar technique, walking with participants around gardens to investigate how they learnt about and engaged with the environment. They concluded that respondents found it easier to verbalise attitudes and feelings when 'in place', producing richer data. When inside respondents usually attempted to be helpful and give the 'right' kind of answers, whereas outside in the gardens, more informal and interesting interactions took place.

While there is a fair degree of consensus on the supposed benefits of using walking interviews, important differences exist in how they are conducted. The most important choice that researchers must make when designing walking interviews is whether the route is set by the interviewer or the interviewee.
Determining a set route in advance has the advantage of focusing the interview on specific places that are relevant to the goals of the research project (Jones, Bunce, Evans, Gibbs, \& Ricketts Hein, 2008). If the researcher wants to garner opinions about specific buildings or paths then this might require following a structured route. Inwood and Martin (2008), for example, used 'roving focus groups' based around a guided tour to explore how students understood the racial tensions inherent to the landscape of the North Campus of the University of Georgia. Paulos and Goodman (2004) similarly used a small number of 'urban walking tours' to evaluate ideas about familiarity and place through interviewer and participants walking to four locations in Berkeley, California. The drawbacks of imposing a predetermined route are that they contrive to make the interviewee do something beyond their normal routine. Kusenbach confined her study to 'natural' go-alongs, following interviewees on journeys they would be making in any case. Contrived go-alongs, it was argued, 'might produce appealing data, but not of the kind that would greatly enhance our understanding of the subjects' authentic practices and interpretations' (Kusenbach, 2003, 464). Further, predetermining routes might be expected to lessen the empowerment felt by interviewees choosing their own route, which may in turn detract from the informality of the encounter.

Fig. 1 presents a typology of walking interviews, plotted along a single axis of route determination and familiarity of the interviewee with place. In our project the routes were determined by the interviewees, but were not necessarily habitual routes and were thus partially made up on the spot. Fig. 1 does not intend to provide a comprehensive list of walking-based interview techniques, but rather an indication of the spectrum of approaches that exist and the key decisions that researchers seeking to use this technique must make.

In spite of the increasing use of walking interviews, little of the work discussed so far pays anything but passing attention to their benefits and pitfalls. Methodological considerations are limited to prior assumptions and subsequent suggestions concerning their ability to yield spatially sensitive insights, while the technical challenges of interviewing outside and on the move are, for the most part, simply not discussed. We believe it is essential to address this shortcoming if the technique is to be taken seriously by

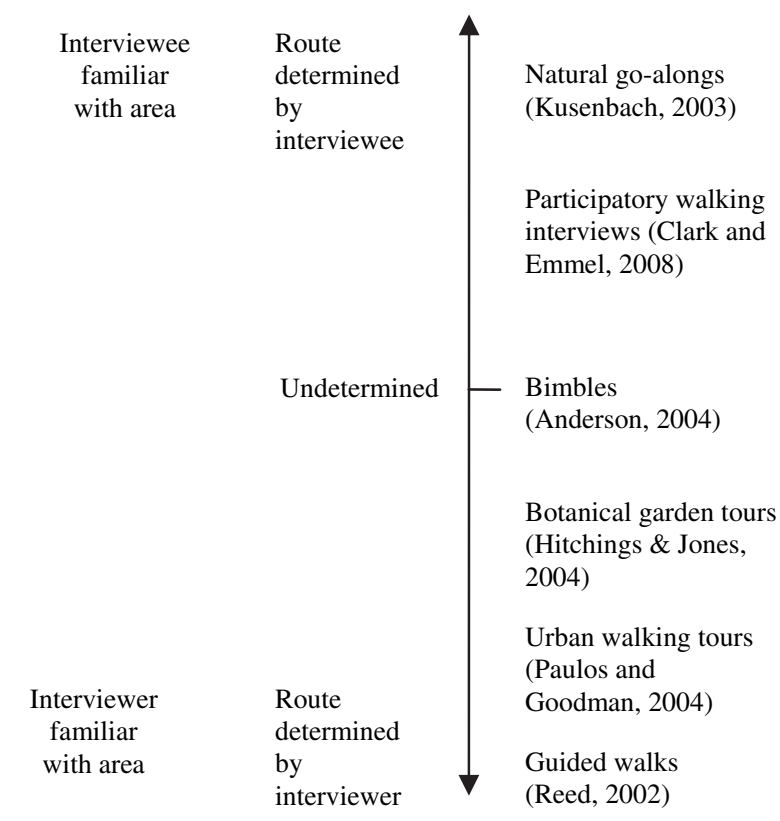

Fig. 1. Typology of walking interviews. 
planning practitioners. Surprisingly, given that the oft-stated purpose of the walking interview is to examine the interviewee's relationship with the environment, this lack of technical consideration means that spatial location is often dealt with rather crudely. A number of projects making use of walking interviews have made little or no attempt to map the data (Anderson, 2004; Clark \& Emmel, 2008; Hall, Lashua, \& Coffey, 2006; Ingold \& Lee, 2008; Kusenbach, 2003; Moles, 2008). Being able to more accurately locate the discussions would add another layer of interpretation to the data collected. One possibility for providing spatial context is the use of video (Pink, 2007), but, particularly when the interviewer is trying to film, walk and talk at the same time, this can both distract from the interview process and produce video which is unsteady and disorientating (although see Mills, Curtis, Kennedy, Kennedy, \& Edwards, 2010, on the use of vehicle-based video in combination with GPS). One of the key goals of the project described in this paper was to tackle the issue of context, producing what we describe as spatial transcripts, allowing spoken words and location to be accurately connected.

Walking interviews differ from sedentary interviews because they can produce quantitative data concerning the routes taken, as well as the more familiar qualitative data derived from the conversational exchange. We acknowledge here that focusing on words and location means that some of the more embodied characteristics of interview practice are lost, rendering this project in some ways rather conservative in the light of recent work on the non-representational (Latham, 2003). This was a deliberate strategy, however, done in part to avoid overburdening the researcher and participant (already wired up for GPS and audio recording) with additional technology such as video cameras. More importantly, however, we felt it was important in a pilot study examining the effect of location to establish a base line of a fairly conventional textual analysis before engaging in further work to look at more nuanced questions concerning the non-textual. Indeed, the complexity of capturing and analysing quantitative spatial data alongside qualitative conversational material may explain the lack of formal studies of the role location/place plays in shaping data collected by walking interviews. The next section addresses this challenge.

\section{The Rescue Geography project: testing the walking interview}

In designing the Rescue Geography project two key methodological questions were identified: what is the relationship between what people say and where they say it; and what are the qualitative and quantitative differences between the data generated by walking and sedentary interviews. Previous research has considered the difficulties of isolating location as a variable in an interviewing process (Elwood \& Martin, 2000). We addressed this methodological challenge by examining data produced by three sample groups: those who undertook a walking interview; those who undertook a sedentary interview; and those who undertook both a sedentary and walking interview.

There are potential pitfalls in this kind of sampling strategy There is the possibility that variations between data are produced by the different people interviewed in each set, rather than the fact that they were walking or sedentary. Attempting to get around this by conducting both walking and sedentary interviews with the same people poses the problem of the sequence in which they are done. We conducted sedentary interviews first, leaving at least one week before returning to conduct the walking interview. It was felt that the cross-contamination between interviews would be lower in this sequence as sedentary interviews are more familiar and walking interviews might be expected to throw up more unexpected data (although we are aware that this choice is to some degree based on untested assumptions concerning walking interviews). While cognizant of the limitations, trends that emerge through comparisons both within and between sample groups were deemed more likely to be attributable to the role played by walking.

The Rescue Geography project took place in the Digbeth district of Birmingham, which has been earmarked for a comprehensive redevelopment scheme. This area was chosen to pilot walking interviews for three reasons. First, the local community were motivated to voice their attachments to the area by the imminent redevelopment plans. Second, Digbeth displays a high degree of landscape diversity, varying from canals and rivers to factories and apartments. This helps highlight people's preferences for walking in different environments and the influence that environmental factors (such as varying noise levels) exert on a walking interview. Finally, the area has a rich but un-stereotyped history, by which we mean it has not entered the formal accounts of local historians which tend to overwrite people's own associations with places - a real problem for researchers in the nearby model village of Bournville, for example. Digbeth is unique in the context of Birmingham, being adjacent to the city centre but characterised by light manufacturing and creative industries with a series of attractive Victorian buildings accompanied by widespread dereliction.

Previous contacts developed in the area were used to access members of the very small residential community. Fliers were distributed in shops and pubs and local community meetings were attended. The project was also discussed on a popular local radio show. It needs to be noted, however, that the walking interview excluded people who were either unable or unwilling to walk for a relatively prolonged period. While we did not set a time limit on the walks, the majority lasted at least half an hour, with the length entirely determined by the interviewees. Some of the older sedentary interviewees were thus willing but unable to conduct a follow-up walking interview.

The possible loss of older residents, with their rich historical attachments to place, represents a drawback to the use of walking interviews and one which may make planning practitioners a little nervous about their use. For sedentary interviewees the interviewer provided a set of local maps to help prompt discussions, attempting to reproduce something of the place-based discussion, although it was left to the participant whether or not to engage with these. The conversations were largely unstructured, but interviewees were made aware that the researcher was interested in stories about Digbeth, with questions exploring personal connections to the area, histories and specific locations which were of interest/significance to the interviewee. This relatively unstructured approach was designed to mirror the walking interview in that it allowed the conversation to drift/flow relatively freely, but with a central narrative around the idea of 'Digbeth', the meaning of which was left for the sedentary interviewees to interpret.

This free interpretation of what 'Digbeth' comprised for the sedentary interviews was mirrored in the walks, with participants allowed to define the route and construct their version of where and what represents Digbeth - they were simply asked to give the researcher a guided tour of the area. As with the sedentary, the walked interviews were largely unstructured with minimal questioning designed simply to maintain the momentum in a narrative about the interviewee's experiences of the place, confining questions to prompts based on things mentioned in the interview. This 'hands-off approach was chosen in order to empower the interviewee as much as possible and maximise the space for narratives to emerge about the place. A global positioning system (GPS) was used to record the geographical tracks of walked interviews alongside an audio recording. 
Location could have been recorded by scribbling notes in situ or inserting prompts into the recording ("we're standing next to the bus station"). This approach was rejected for two reasons. First, a GPS record meant that the researcher could concentrate on the interview, rather than note taking and did not need to interrupt the flow of the conversation to insert prompts. Second, and more importantly, it meant that the apparently ephemeral and trivial comments - which might not provoke the researcher in the field to note location - could be geo-located, opening up a much more complete spatial analysis of the transcripts. Thus the GPS was not simply a technophillic add on to the project, but fundamental to the way in which the textual data could subsequently be spatially analysed.

To bring together the audio and GPS records it was necessary to match the starting point of each recording. This was helped by synchronising the time stamp on the audio recorder to that of the GPS, but in practical terms, starting the audio recording first and then the researcher inserting an audio prompt ("that's recording") when the GPS log was turned on proved a very effective means of doing this. The audio recordings were transcribed in a word processor using a table structure, with a column of times representing the position on the recording. Each row of the table thus represented $10 \mathrm{~s}$ worth of text. The table format was used because it allowed for easy transfer into a spreadsheet for linguistic analysis and subsequently into the GIS.

Attempts have been made to investigate the issue of place attachment using GIS, although this can run the risk of reducing complex data through quantification (Brown \& Raymond, 2007). Qualitative GIS is becoming an increasing common mode of data analysis (Cope \& Elwood, 2009; Kwan \& Knigge, 2006) and the spatial transcripts created by Rescue Geography sits within this emerging field. It should be emphasised, however, that we did not adopt a strictly public participatory approach to the GIS (Sieber, 2006; Wang, Yu, Cinderby, \& Forrester, 2008). Our participants 'produced' the data through the action of walking and talking, but were not actively involved in the analysis of the resultant maps, although these were subsequently made available online. While we felt this involvement was not necessary on this particular project, there is clear scope for communities to become more directly involved in the mapping practices through web 2.0 techniques (Miller, 2006). This potential to extend the technique could add value from a planning practitioner perspective in terms of using walking interviews within a public consultation process.

Fourteen walking interviews and fourteen sedentary interviews were conducted with separate sample groups, while six double interviews were conducted. Double interviews were particularly hard to arrange and a number fell through during the course of the research. This is perhaps understandable, due to both the excessive time demands made on double interviewees and the concern on their behalf that they "wouldn't have anything else to say". The project was promoted to participants as an oral history and a means to have their voices heard within the regeneration planning process, given that these factors would be of greater interest to encourage recruits than the methodological questions. We did not, however, conceal the fact that we were also interested in developing the technique itself and made it clear to participants that the project had multiple goals.

\section{Modes of analysis}

Walking interviews produce a wealth of data in the form of time-stamped interview transcripts and GPS tracks. We undertook analysis in two stages, first examining the relationship between location and speech, and secondly exploring differences between data generated by walking and sedentary interviews. The effect of a series of environmental factors on interview length and speed of walk were interrogated, including varying noise levels, the busyness of the street and weather conditions. We also examined the distance between specific places and the location where they were being talked about. At a more discursive level we analysed the extent to which the environment acted as a prompt within both walking and sedentary interviews, through a linguistic analysis of each place mentioned by the interviewee.

Speech objects, defined as places mentioned by the interviewee, were used as the primary units within the linguistic analysis. Subsequent categories captured relevant characteristics for each speech object, such as the type of place it is, whether it still exists and so forth. The use of speech objects and their discursive categories drew on basic insights from environmental psychology (for example, Canter, 1986; Kaplan \& Kaplan, 1982; Proshansky, Fabian, \& Kaminoff, 1983), concerning the perceptual salience of place, which relates to the number and intensity of highly noticeable features. Further spatial elements were also recorded, such as the use of a secondary place to contextualise the primary speech object (so for example, "The Institute, you know, on the High Street"). This attempt to capture the relation between places mentioned and position in the landscape using linguistic means was intended to complement subsequent GIS analysis of the relation between speech objects and physical location.

The most technically innovative level of analysis involved mapping the conversation in a GIS through the creation of spatial transcripts. Once protocols for transcription and GPS recording were established the task of linking the two datasets was relatively straightforward - saving the table of text from the spreadsheet in a tab-delimited format which could be read by a GIS. This file was then connected to the GPS log using a simple 'join' function within ArcGIS, linking each point in the conversation to the relevant point in space. The content analysis of the interviews described above was recorded as additional columns within the database, for instance, to indicate the speech object at a given point in the conversation. Overlaying data from multiple interviews allows patterns to emerge, for example strongly expressed preferences for particular features of the area. This kind of analysis would simply not have been possible without the connection of the transcript content analysis and the GPS data. Although this technique is innovative, it is not particularly technically challenging nor significantly more time consuming than dealing with conventional interview data. As such, it is something which is realistic for planning practitioners to consider utilising. The spatial transcripts were subsequently exported to Google Maps/Earth using a simple KML conversion program. This produced appealing interactive maps which proved to be an effective tool on the website with which to engage interviewees and various other stakeholders with the project (Fig. 2, Multimedia Content 1, 2).

\section{Analysis}

\section{The relationship between location and speech}

A background noise survey was undertaken sampling decibel levels throughout the study area during a typical working day. These were interpolated using an inverse distance weighted algorithm in ArcGIS in order to produce a noise 'surface' (Fig. 3). Values from this surface were then connected to each point on the combined log of all the GPS points for the walked interviews. This allowed a comparison to be made of the proportion of GPS points recorded for the walk falling into different decibel ranges against the proportion from the original sample points. This is a somewhat quick-and-dirty method, but provides a basis for initial conclusions to be drawn. As illustrated in Fig. 4, there is a general trend towards 


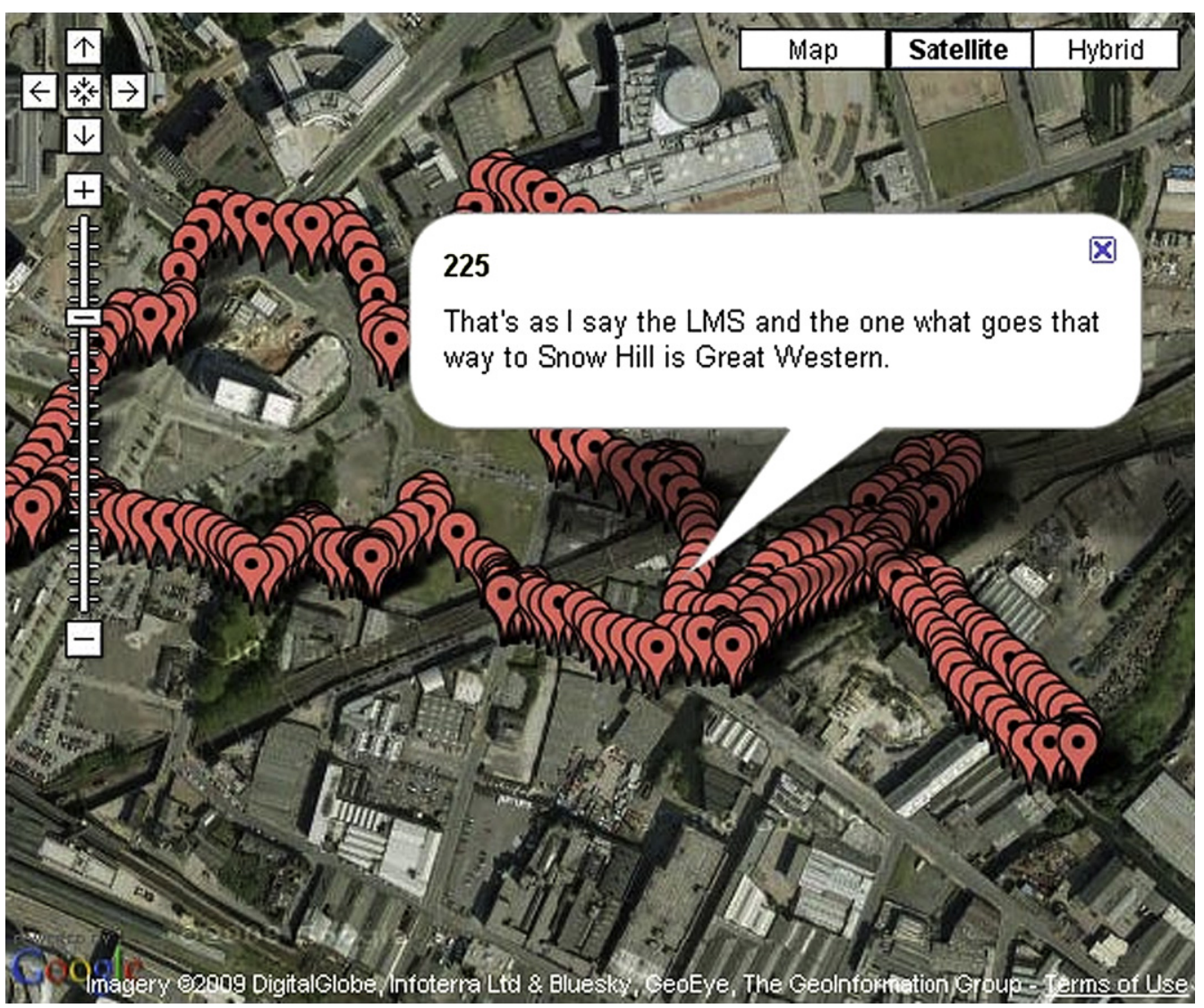

Fig. 2. Spatial transcript displayed in Google Maps. Source: Base photograph, Google, 2008.

walking interviews taking place on routes that are slightly noisier than an 'average' route in Digbeth.

To investigate this relationship further we constructed a typology of different linear features along which the interviewees could walk within the area. As would be expected, the noisiest areas were primary distributor roads, such as Digbeth High Street, while the quietest areas were the canal towpath and pedestrianised routes away from traffic. By examining the timestamps on the GPS logs it was possible to determine how long interviewees spent in each different zone, and, from the distance walked, their average speed in each. Fig. 5 invalidates the intuitive assumption that interviewees would pass more rapidly through noisier types of area. This is important because our concern was that certain areas would gain less attention from interviewees as they hurried through to escape the din of stationary buses and heavy traffic. Both data generated from the interpolated noise surface and the linear typology indicate that there is actually a slight tendency towards spending more time in noisier areas. There are a number of possible explanations for this: greater familiarity with the main roads as a means to traverse the space; a sense of greater personal safety in the busy areas; fewer obstacles/road crossings to negotiate on the towpath; and there simply being more things to talk about and linger over in the busier areas.

Other studies have suggested that weather has some influence on walking interviews (Clark and Emmel 2008). For Rescue Geography, length of interview was compared against prevailing weather conditions using hourly data from the nearby meteorological station in Edgbaston. The time and date of these interviews was established in advance and none were cancelled due to weather conditions. With only one instance of heavy rain during an interview it is impossible to draw firm conclusions on the effect of precipitation. For temperature and windspeed, however, there are simply no clear patterns: the two longest interviews, for example, took place on the coldest and second hottest days. Assuming interviewees are appropriately dressed for the prevailing conditions, the relatively mild variations of climate in the English Midlands do not appear to pose any great barrier to the walking interview process.

The speech object category in the combined interview dataset was used to identify the features within the study area which generated the most stories. Analysis was then undertaken on the spatial distribution of identified speech objects for each of these features. In addition, the spatial transcripts were searched for instances of the place name cropping up in the text without a story attached. Using the GIS, the average distance was calculated between the feature and the points at which there were specific mentions or speech objects within the transcript. As indicated in Fig. 6 there is a slight tendency for the speech objects to occur a little further away on average than simple mentions of the place name, though in general the two are broadly in line with each other. At first glance it seems there is no consistency in terms of average distance from location discussed. Looking behind the data, however, the ability of interviewees to see the feature appears to have a significant influence. Those features with the highest average distance-to-mention, the Bullring, Millennium Point and Curzon Street Station, are highly visible. Examining the spatial distribution of 'mentions' for these features reveals some clustering at points where there are unobstructed sightlines. There is an excellent view of the Bullring, for example, from a hill at the southern end of Digbeth, over a kilometre away, with a number of mentions occurring at this point, clearly skewing the average 

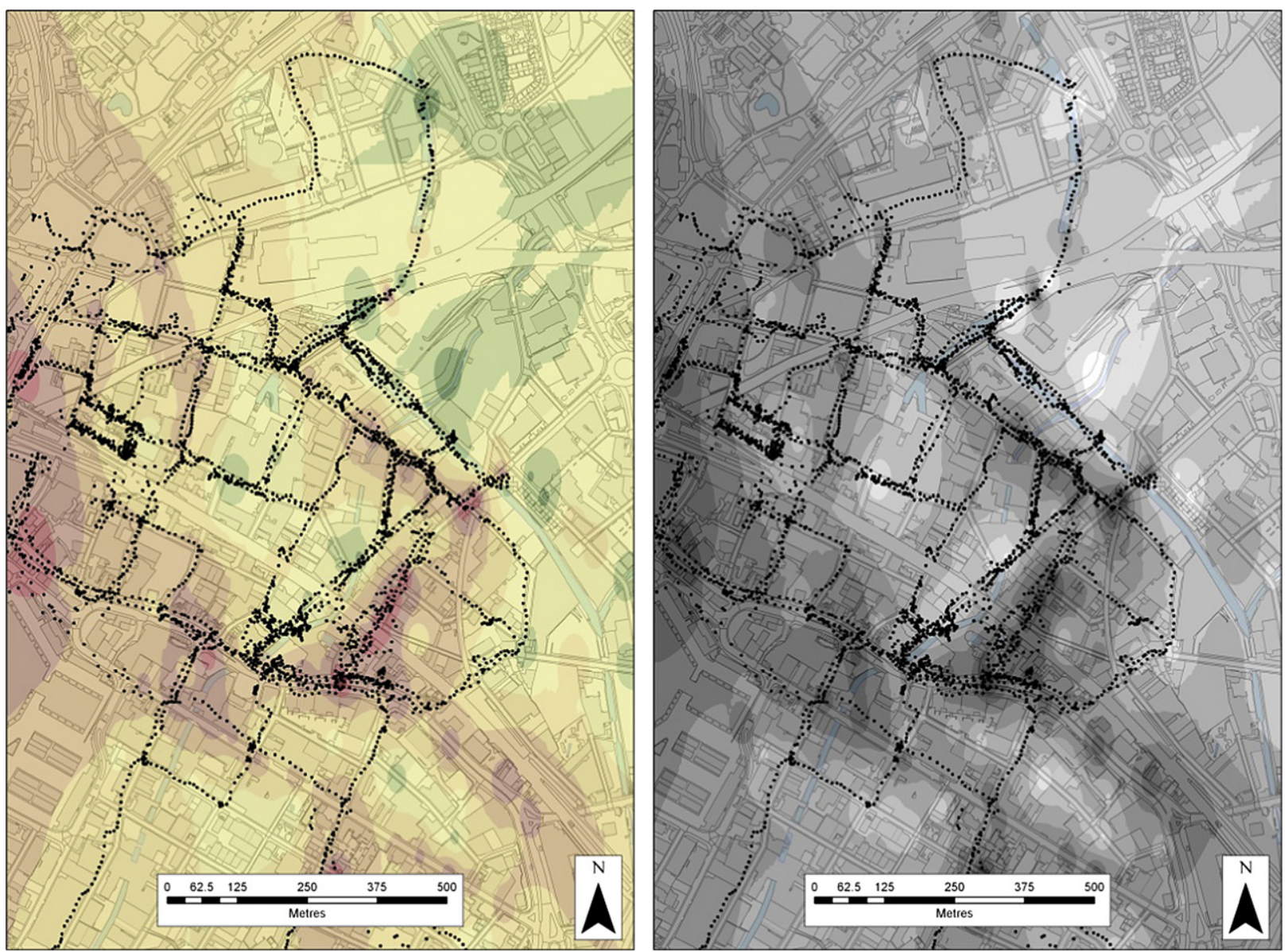

Fig. 3. Background noise 'surface' and the aggregate tracklog of walked interviews [colour \& b/w versions]. Source: Base map Ordnance Survey/Digimap 2008

distance-to-feature. Conversely, the canal network, Latif's warehouse and the Typhoo complex are much less visible unless nearby, reflected in the much shorter distance-to-mention. An interesting exception to this is the railway arches, which have a relatively lowdistance-to mention and yet are very large and visible elements in the urban landscape. As Fig. 7 illustrates, however, the railway arches feel much more dramatic when in their immediate proximity, appearing to be of a similar scale to surrounding buildings when viewed from a distance. While not all mentions and speech objects originated within view of the feature, sightlines clearly

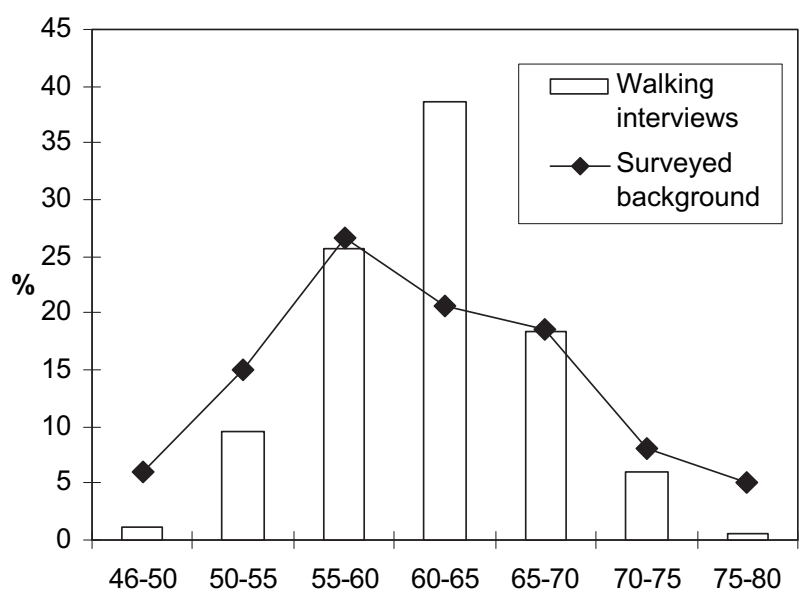

Fig. 4. Comparison of background noise samples and interpolated background noise for walked interviews within different decibel ranges. influence how people discuss the urban landscape, affecting average distance between features and where they are talked about. This clearly gives strong support to an intuitive assumption that proximity to and visibility of features are significant in prompting the data generated by walked interviews.

\section{Differences between data generated by walking and sedentary} interviews

Aggregating the data for each sample group allows some interesting comparisons to be made. The average length of the walking interviews (54 min) was considerably longer than that of the sedentary interviews ( $37 \mathrm{~min}$ ). The fact that walking interviews tend to last longer than sedentary suggests two things. First, the rhythms of walking allow for natural breaks in the conversation which can

\section{Average speed (metres per second) walked by} interviewees in each zone type within Eastside

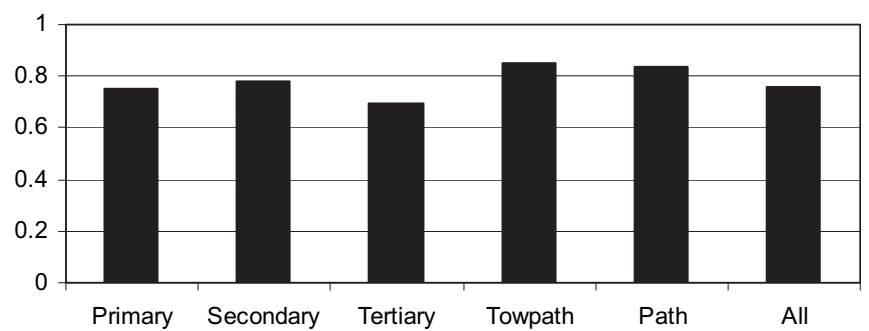

Fig. 5. Average speed walked by interviewees in different zone types. 


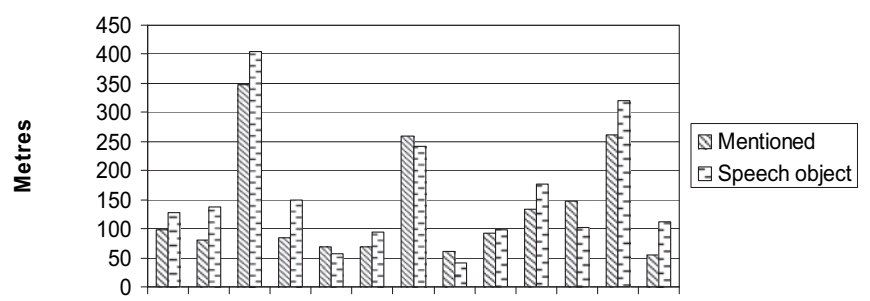

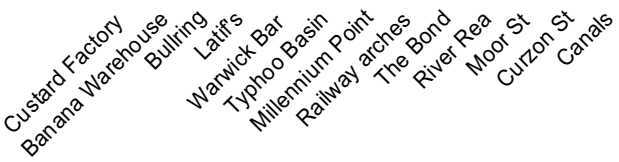

Fig. 6. Average distance from point of mention and speech object to location being discussed. then be picked up again as the walk progresses, rather than it signalling the end of the interview as it might in a sedentary context. This, in effect, makes it easier for the researcher to keep the conversation going than in an unstructured sedentary interview, potentially a significant advantage to the less skilled researcher. Secondly, and related to this, it suggests that walking interviews do make it easier to engage with a respondent's understandings of place. Interestingly, looking at the number of places mentioned per hour, gives a similar relative average of 42 places for walking interviews compared to 44 for the sedentary. Drilling down reveals that the walking interviews produce a higher number of places related to the study area (34, as compared to 31 average mentions per hour) as well as, by dint of the longer average interview time, a greater absolute number of place mentions.

The walking interviews also varied more in terms of both length and number of places mentioned, showing a standard deviation of
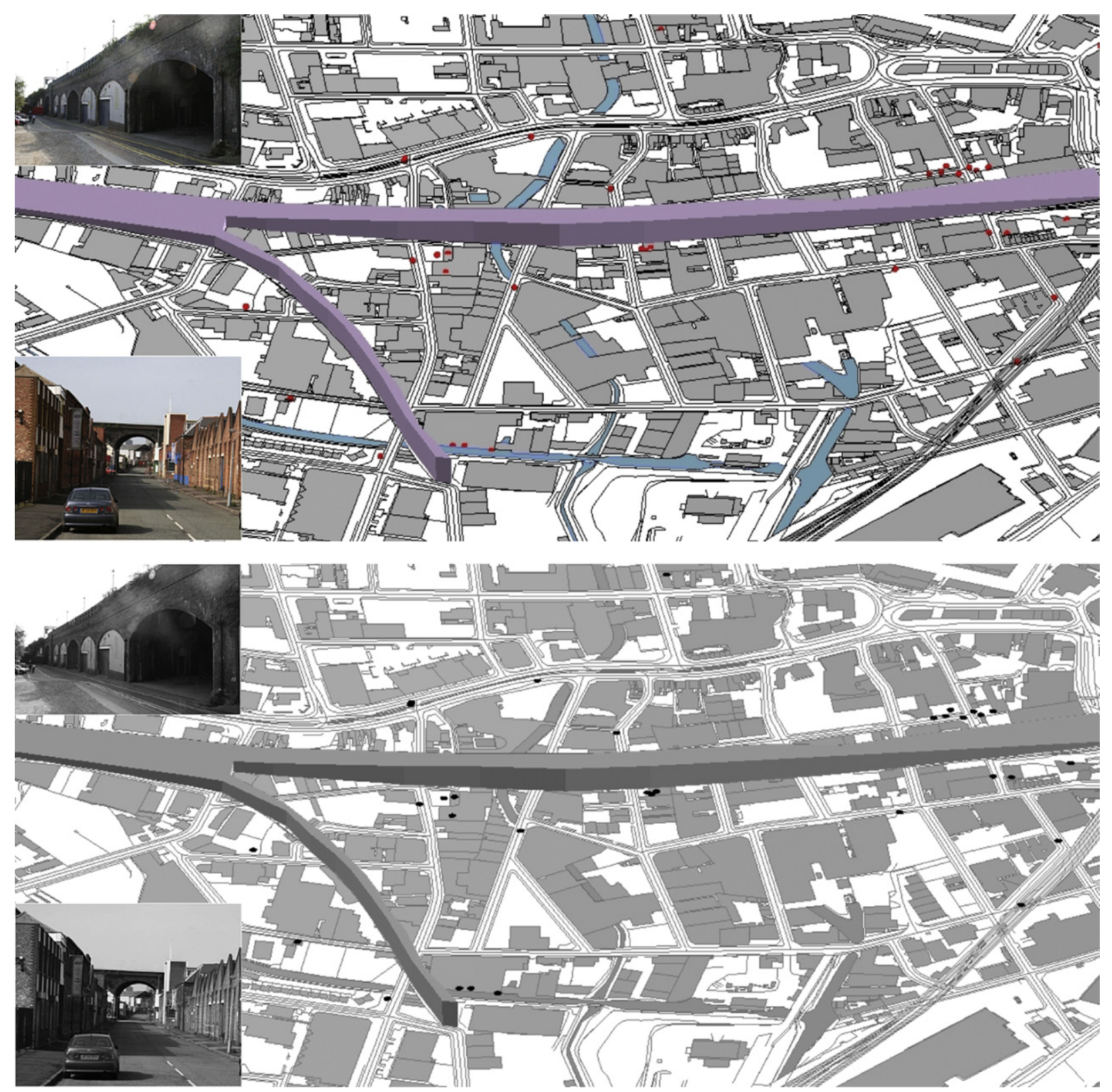

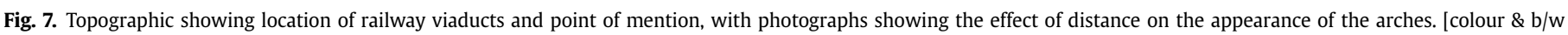
versions]. Source: Base map Ordnance Survey/Digimap 2008. Photos, authors. 
20 min and 15 places compared to $12 \mathrm{~min}$ and 12 places in the sedentary interview sample. This might be expected as walking interviews cause interviewees to focus closely on the place in question, highlighting different levels of knowledge about an area in the form of longer or shorter walks. Sedentary interviewees, meantime, tended to drift onto other topics when they had exhausted their knowledge of the area under question.

A critical question for researchers using qualitative data concerns how the discourses of place produced by walking and sedentary interviews differ. The data indicates that walking interviewees tend to talk about their relation to place with less prompting by the interviewer, with $97 \%$ of places coming up spontaneously in conversation. Examining the spatial descriptor for the places mentioned in walking interviews shows that $70 \%$ were prompted by sight - i.e. by walking past or near to them. By comparison, sedentary interviews averaged five prompts per interview, which accounted for $19 \%$ of the places mentioned. This would seem to support the hypothesis that walking interviews produce more spontaneous data as elements of the surrounding environment prompt discussion of place, acting as what de Leon and Cohen (2005) call 'walking probes'.

Comparing the types of places mentioned in Table 1 adds detail to this picture. Sedentary interviews were dominated by mentions of general 'areas' outside Digbeth, rather than specific features within it, but the remaining categories give a good idea of features that sedentary interviewees considered to be important within Digbeth. Similarities between place mentions in the walking and sedentary interviews include a focus on places related to service functions (retail, leisure etc.) and roads, which are used as spatial markers. There were significant differences between the two types of interviews in the relative weightings of public buildings, factories and infrastructure. In short, walking interviews seem to highlight distinctive area-specific features like canals, railway viaducts and manufacturing units more effectively. The greater emphasis on factories at least partially explains the higher proportion of places mentioned in the walking interviews that still exist but with a different use (18\% compared to $7 \%$ for the sedentary interviews). Approximately $7 \%$ of places mentioned in each interview sample no longer existed. These findings are perhaps slightly surprising, given that the sedentary interviews tended to take a biographical format and thus might have been expected to produce more historical places that either no longer exist or exist under a different use.

In order to evaluate the quality and potential utility of the data produced, it is necessary to dig deeper into the discursive character of the walking interview and interrogate what is actually said about each place mentioned. For example, a transcript containing lots of place names without any subsequent information attached to them

Table 1

Types of places mentioned in walking and seated interviews.

\begin{tabular}{llll}
\hline Walking & Seated & Walking (Both) & Seated (Both) \\
\hline Service (25\%) & Area (34\%) & Service (28\%) & Area (27\%) \\
Factory (15\%) & Service (20\%) & Factory (15\%) & Service (25\%) \\
Road (13\%) & Road (17\%) & Road (13\%) & Road (19\%) \\
Infrastructure & Public (7\%) & Infrastructure & Public (9\%) \\
$\quad(13 \%)$ & & $(12 \%)$ & \\
Public (13\%) & Infrastructure (6\%) & Public (12\%) & Factory (6\%) \\
Area (6\%) & Factory (6\%) & Area (4\%) & Infrastructure (5\%) \\
Religious (4\%) & Religious (4\%) & Religious (4\%) & Religious (3\%) \\
Domestic (4\%) & Cultural (3\%) & Domestic (4\%) & Cultural (3\%) \\
Environmental & Environmental & Environmental & Environmental \\
$\quad(3 \%)$ & $(2 \%)$ & $(3 \%)$ & $(2 \%)$ \\
Cultural (3\%) & Domestic (1\%) & Cultural (5\%) & Domestic (1\%) \\
Other (1\%) & Other (0\%) & Other (0\%) & Other (0\%) \\
\hline
\end{tabular}

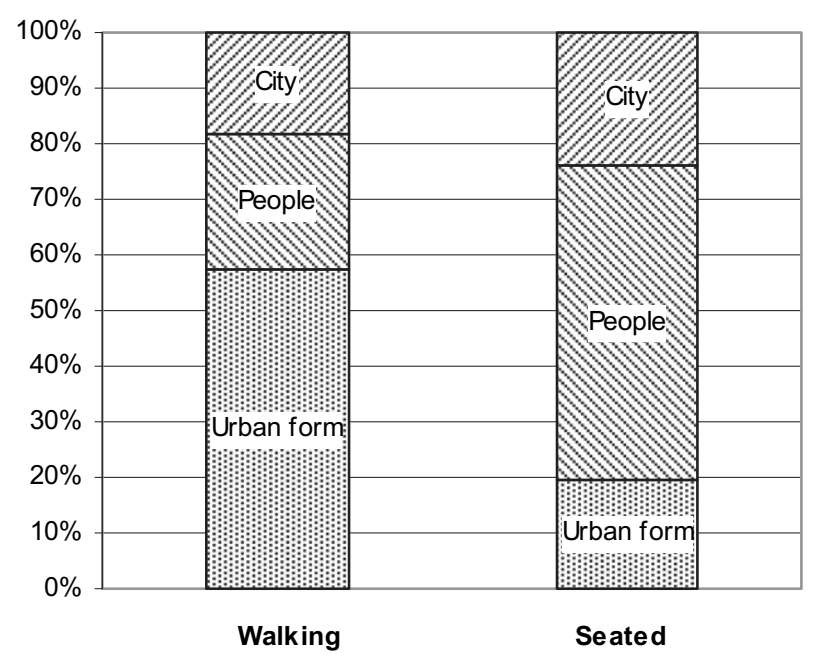

Fig. 8. Topic of stories told.

will often be of less use to researchers than a transcript containing a small number of places with revealing stories about each. As would be expected given the greater number of places mentioned in the walking interviews, they produced 23 stories per interview compared to 13 for the sedentary interviews. This pattern is reinforced by the sample that undertook both, which displayed 22-10 respectively. Walking interviews also have a slightly higher 'place to story' ratio, with $60 \%$ of places mentioned being accompanied by a story compared to $56 \%$ for sedentary interviews.

While these differences are marginal, the topic of stories told differs markedly. As Fig. 8 shows, walking interviewees liked talking about specific buildings and environmental features and their use ( $57 \%$ of stories told), whereas the sedentary interviews tended to produce narratives that, although prompted by places, focused on people (58\% of stories told). This difference was replicated in the group that undertook both types of interview, offering further evidence that walking interviews produce data about the way in which people relate specifically to place, rather than the interviewee's biographical account of their history 'in place' associated with the temporal narrative form of sedentary interviews. Walking interviews produce a decidedly spatial and locational discourse of place, which is structured geographically rather than historically. Mapping these interviews produces a narrative that unfolds through place, organising experiences spatially rather than temporally.

\section{Conclusions: the walking interview as research method}

This pilot project provides an evidence base to support the previously untested hypothesis that walking with interviewees generates more place-specific data than sedentary interviews. Walking interviews tend to be longer and more spatially focussed, engaging to a greater extent with features in the area under study than with the autobiographical narrative of interviewees. This also indicates that walking interviews serve as a less productive mode where autobiographical narratives are the researcher's object of study. These patterns emerged consistently from both the comparison between groups who did either a sedentary or a walking interview, and the comparison within the group who did both.

The relative position of interviewee and feature is significant as the walks take place, with both proximity and a clear line of sight acting to prompt discussion. There are, however, some slightly counter-intuitive findings from this study, including the effect of 
high levels of background noise, which does not appear to be a significant barrier to interviewees spending time in a particular space. Similarly, ambient temperature does not appear to have any significant effect on how long interviewees are willing to walk for, although this may be come a factor in more extreme climates. Further work would be useful in different contexts, exploring, for example, whether similar results are produced by walking interviews in suburban or rural areas.

All of this has great potential significance for practitioners. Walking interviews have been demonstrated as a highly productive way of accessing a local community's connections to their surrounding environment. This is critical because people's relationships with place keys into contemporary policy issues surrounding sustainability. Decision-making, particularly in the public sphere, must take account of local histories and the preferences of local populations if it is to be fair and sustainable, linking the past to the future in a sensitive way. Indeed, this has been acknowledged in recent English policy, with 'sense of place' (however vaguely defined) being seen as a key component in creating sustainable communities and lifetime neighbourhoods (CLG, 2007). This logic also holds for decisions made in the private sector, which is under increasing economic pressure to produce developments that are both more unique and socially sustainable over the long-term in order to win contracts and attract investment (Evans, Jones, \& Krueger, 2009). Being able to capture the distinctive characteristics of place can help meet these challenges and one practical means for practitioners to achieve this is through undertaking walking interviews with community members.

In a similar vein, the potential to use this technique for public consultation is obvious for a whole range of planning issues, ranging from siting controversies to master-planning. Certainly our experiences communicating the results of the project to planners, developers and architects has highlighted the huge appeal that spatialised data holds. Representing qualitative data in map form makes them instantly more appealing to decisionmakers. They offer an opportunity to make people's values and local histories count more within a range of development processes. But the power of maps is well documented within geography (Wood \& Fels, 1993), and care is required when using them to represent qualitative data. Maps simultaneously increase the potential damage that can be caused by misinterpretation and over-simplification. Further work exploring the potential to apply this technique in real-world decision-making scenarios is needed to understand the most effective ways in which to analyse and represent data.

A small scale pilot study, such as the one described here, prompts as many questions as it answers, and there is a need for further work to refine the technique and test its potential applications. Walking interviews have been demonstrated to be highly effective in accessing place attachment but the mode of analysis deployed here using GIS technology could be used to emphasise the locational elements of place, as distinct from more humanist conceptions. Care is required to avoid being overly seduced by the positivist potential of this method. Nonetheless, the potential contribution to current policy agendas is obvious, and geographers - able to marry a rich disciplinary understanding of place to the analytic and representational power of GIS - are ideally placed to contribute.

\section{Acknowledgements}

The research on which this paper is based was funded by the UK's Economic and Social Research Council (grant number RES-0022-2375). For more information on the project see www. rescuegeography.org.uk We would like to thank all the participants for their time and their stories and our research assistant, Jane Ricketts Hein, for undertaking the interviews.

\section{Appendix. Supplementary data}

Supplementary data associated with this article can be found, in the online version, at doi.10.1016/j.apgeog.2010.09.005

\section{References}

Adams, M., \& Guy, S. (2007). Editorial: senses and the city. Senses \& Society, 2, 133-136.

Anderson, J. (2004). Talking whilst walking: a geographical archaeology of knowledge. Area, 36, 254-261.

Bijsterveld, K. (2010). Acoustic cocooning: how the car became a place to unwind. Senses \& Society, 5, 189-211.

Bissell, D. (2010). Vibrating materialities: mobility-body-technology relations. Area Early View.

Brown, G., \& Raymond, C. (2007). The relationship between place attachment and landscape values: toward mapping place attachment. Applied Geography, 27, 89-111.

Canter, D. (1986). Putting situations in their place: foundations for a bridge between social and environmental psychology. In A. Furnham (Ed.), Social behaviour in context (pp. 208-239). London: Allyn \& Bacon.

Carpiano, R. M. (2009). Come take a walk with me: the "go-along" interview as a novel method for studying the implications of place for health and well-being. Health E Place, 15, 263-272.

Clark, A., \& Emmel, N. (2008). Walking interviews: more than walking and talking Presented at 'Peripatetic Practices': a workshop on walking (London) March 2008.

CLG. (2007). Towards lifetime neighbourhoods: Designing sustainable communities for all. A discussion paper. London: CLG.

Cope, M., \& Elwood, S. (2009). Qualitative GIS: a mixed methods approach in Editor ed^eds Book Qualitative GIS: A mixed methods approach, Volume Sage, City

Edensor, T. (2007). Sensing the ruin. Senses \& Society, 2, 217-232.

Elwood, S., \& Martin, D. (2000). "Placing" interviews: location and scales of power in qualitative research. The Professional Geographer, 52, 649-657.

Evans, J., Jones, P., \& Krueger, R. (2009). Organic regeneration and sustainability or can the credit crunch save our cities? Local Environment: The International Journal of Justice and Sustainability, 14, 683-698.

Fincham, B., McGuinness, M., \& Murray, L. (2010). Mobile methodologies in Editor ed^eds Book Mobile methodologies, Volume Palgrave Macmillan, City.

Hall, T., Lashua, B., \& Coffey, A. (2006). Stories as sorties. Qualitative Researcher, 3, $2-4$.

Hitchins, R., \& Jones, V. (2004). Living with plants and the exploration of botanical encounter with human geographic research practice. Ethics, Place and Environment, 7, 3-18.

Ingold, T., \& Lee, J. (2008). Ways of walking: Ethnography and practice on foot. London: Ashgate.

Inwood, J. F. J., \& Martin, D. G. (2008). Whitewash: white privilege and racialized landscapes at the University of Georgia. Social $\mathcal{E}$ Cultural Geography, 9, 373-395.

Jones, P., Bunce, G., Evans, J., Gibbs, H., \& Ricketts Hein, J. (2008). Exploring space and place with walking interviews. Journal of Research Practice, 4. (np).

Kaplan, S., \& Kaplan, R. (1982). Cognition and environment. New York: Praeger.

Kusenbach, M. (2003). Street phenomenology: the go-along as ethnographic research tool. Ethnography, 4, 455-485.

Kwan, M. P., \& Knigge, L. (2006). Doing qualitative research using GIS: an oxymoronic endeavor? Environment and Planning A, 38, 1999-2002.

Latham, A. (2003). Research, performance, and doing human geography: some reflections on the diary-photograph, diary-interview method. Environment and Planning A, 35, 1993-2017.

Laurier, E., \& Philo, C. (2003). The region in the boot: mobilising lone subjects and multiple objects. Environment and Planning D, 21, 85-106.

de Leon, J., \& Cohen, J. (2005). Object and walking probes in ethnographic interviewing. Field Methods, 17, 200-204.

McDonald, S. (2005). Studying actions in context: a qualitative shadowing method for organisational research. Qualitative Research, 5, 455-473.

Merriman, P., Revill, G., Cresswell, T., Lorimer, H., Matless, D., Rose, G., et al. (2008). Landscape, mobility, practice. Social E' Cultural Geography, 9, 191-212.

Middleton, J. (2009). 'Stepping in time': walking, time, and space in the city. Environment and Planning A, 41, 1943-1961.

Miller, C. (2006). A beast in the field: the Google Maps mashup as GIS/2. Cartographica, 41, 187-199.

Mills, J., Curtis, A., Kennedy, B., Kennedy, S., \& Edwards, J. (2010). Geospatial video for field data collection. Applied Geography, 30, 533-547.

Moles, K. (2008). A walk in thirdspace: place, methods and walking. Sociological Research Online, 13. (no pagination). 
Paulos, E., \& Goodman, E. (2004). The familiar stranger: anxiety, comfort, and play in public places in Editor ed^eds Book The familiar stranger: Anxiety, comfort, and play in public places, Volume ACM, City.

Pink, S. (2007). Walking with video. Visual Studies, 22, 240-252.

Proshansky, H., Fabian, A., \& Kaminoff, R. (1983). Place-identity: physical world socialization of the self. Journal of Environmental Psychology, 3, $57-83$.

Reed, A. (2002). City of details: interpreting the personality of London. Journal of the Royal Anthropological Institute, 8, 127-141.

Ricketts Hein, J., Evans, J., \& Jones, P. (2008). Mobile methodologies: theory, technology and practice. Geography Compass, 2, 1266-1285.

Sheller, M., \& Urry, J. (2006). The new mobilities paradigm. Environment and Planning $A, 38,207-226$.
Sieber, R. (2006). Public participation geographic information systems: a literature review and framework. Annals of the Association of American Geographers, 96, 491-507.

Solnit, R. (2001). Wanderlust: A history of walking. London: Verso.

Spinney, J. (2006). A place of sense: a kinaesthetic ethnography of cyclists on Mont Ventoux. Environment and Planning D, 24, 709.

Wang, X., Yu, Z., Cinderby, S., \& Forrester, J. (2008). Enhancing participation: experiences of participatory geographic information systems in Shanxi province. China Applied Geography, 28, 96-109.

Wood, D., \& Fels, J. (1993). The power of maps. London: Routledge.

Wylie, J. (2005). A single day's walking: narrating self and landscape on the South West Coast Path. Transactions of the Institute of British Geographers, 30 234-247. 